\title{
The ethics of investment
}

\section{The City of London Geoscience Forum recently discussed ethical issues surrounding investment in the extractive industries. Mark Steeves* discovered that the debate is not clear-cut}

Ethical investment is something of a hot topic. Alternatively known as socially responsible or sustainable investment, the idea is that financial investments should also bring about positive change, socially or environmentally. On 31 May 2018, the City of London Geoscience Forum - a group that aims to reach out and build bridges with City professionals and corporate sponsors of the Society-held a debate entitled 'Investing in the Extractive Industries'. The second of the group's series on 'Ethics in the Extractive Industries', the discussions emphasised that to achieve a certain standard of living for all people globally, we should perhaps consider it unethical not to invest in the extractive industries. But, there was a sting in the tail, a valuable reality check for the assembled audience of mining and oil industry executives, lawyers, investors and bankers: there are severe environmental and societal consequences associated with the extractive industries and investors need to be more knowledgeable in this regard.

Hosted by law firm, NortonRose Fulbright, in their London offices, the event was ably chaired by Colin Melvin (see speaker details, online). Colin's principal message was to suggest there is a distinction between sustainable investment and ethical investment-the former is an objective measure, the latter more subjective. $\mathrm{He}$ also referred to BlackRock chairman Larry Fink's 2018 letter to CEOs that challenged companies on their role in the community; their impact on the environment; adapting to technological change; and adjusting to an increasingly automated world.

\section{Common good}

Adam Matthews spoke first, for the Church of England (CoE), which has over £12 billion of assets under management. Despite some recent misleading headlines in national newspapers, the CoE is committed long-term to the extractive industries and understands their economic, developmental and social significance. Whilst the CoE have disinvested on climate grounds from companies that generate more than $10 \%$ of their revenue from tar sands and thermal coal, the CoE's concerns are to do with the common good. Fundamentally, Adam stated it was about responsibility: "The moment ground is broken, responsibility flows through the company, government and investors to ensure best practice and that royalties benefit wider society-the common good". Adam talked of human rights, the environment, health, safety and governance, citing Samarco's 2015 Bento Rodrigues dam disaster in Brazil and the 2012 South African Marikana massacres. Adam told us that minority shareholders and co-venture partners have "nowhere to hide" and are as subject to scrutiny as major listed multinational mining and oil companies.

David Nussbaum, CEO of The Elders, with a nod to our hosts-lawyers - said that "being legal is not the same as being ethical": ethics imply constraints beyond the minimum required by law. Extracted products are not socially useless and have value to humanity, but David has been in the business of holding companies and governments to account for many years and is concerned about the process of extraction, bribery and the environment. Extractive industries have aggravated inequality and exclusion in many societies around the world and David asserted that the expectations of the people of the world are increasing. Nobody can argue with that last point.

\section{Complex challenges}

It fell to retired long-term Shell and Exxon executive Glen Cayley to defend the petroleum industry, which he did, determinedly and robustly. Glen acknowledged the complex challenges faced by society, but he also drew attention to the 1-in-3 people around the world with no access to electricity, the 1.2 billion people awaiting their first light bulb, the 3 billion people who cook over solid fuel fires: these people will not be amongst those who question ambitions for economic growth and a determination to improve quality of life. Glen acknowledged climate change. He suggested that enlightened governments, academia, industry and the most gifted entrepreneurs

will tackle the threats to our world without crushing the prospects for the poorest. Glen exhorted us to inspire future engineers and scientists to innovate and invent, to meet the world's challenges. He concluded by asking "Is it ethical not to invest?"

Mike Harris, our last speaker, provided the reality check. He has had a life time working in the mining industry, retiring from Rio Tinto in January 2018. Now a Visiting Professor in the Department of Earth Science \& Engineering at Imperial College London, Mike delivers lectures on 'The Morality of Mining'. Some of the audience will have known what to expect. I didn't.

Mike recited a ream of government and agency policy statements, industry statistics and estimates about many minerals and ores, but for me, those around copper were a revelation and most illustrative. According to the International Energy Agency, the number of electric vehicles worldwide is set to triple by 2020 to 13 million, and these vehicles use approximately 4 times more copper than conventional combustion engine vehicles. It is estimated that every new megawatt of wind power will require around 3.6 tonnes of copper and each new megawatt of photovoltaic solar power another 4 to 5 tonnes of copper. 
Yet, there is only one copper mine in the world that produces 1 million tonnes per year. About 200 of the currently producing copper mines are forecast to reach the end of their productive lives by 2035 and less than half a dozen large new copper mines have been discovered in the last 25 years. Mike had a similar tale to tell about iron ore, lithium, cobalt, nickel and so on.

\section{Big questions}

Mike asked some big questions: are we comfortable with our assumptions on who owns natural resources-is it local government, the people who live there, the people of that country, or have those resources become global resources? Who should benefit from mining those resources, and who has the moral right to restrict the availability of commodities to the vast numbers of people going from a rural to an urban environment? We were reminded of some basic science and the true costs and risks of our actions: for instance, at Rio Tinto, the operational total $\mathrm{CO}_{2}$ equivalent emissions are around 30 million tonnes per year, which does not include the more than
520 million tonnes of $\mathrm{CO}_{2}$ equivalent emitted by customers using its iron ore to make steel. Is steel in the headlines? No, except in terms of the social cost of losing jobs.

Where will the new materials come from to supply the renewable technologies and infrastructure, and to supply those people aspiring to lifestyles more akin to our own? The practical answer to this increase in demand will be to mine ever lower grade ores in ever larger mines, with the consequent environmental issues, and to increase prices.

I wondered about the social consequences: is the price we pay a sufficiently good one to allow developing nations to enjoy the same benefits we in the West already derive from 'their' commodities? And if it is, can the governments of developing countries be trusted to manage the wealth responsibly, productively and for the benefit of all their people? Evidently, to judge from the migrant flows from African and other resource-rich countries, the answer is another emphatic no.

As a Friend of the Geological Society and not a geologist, I ask myself whether geoscientists should more determinedly put themselves forward as responsible guardians of Earth's riches, not only to counter their social media reputation as plundering and exploitative extractors of resources for their own personal enrichment, but because they know what they're talking about! With their experience of extracting Earth's resources and having an evidence-based idea of the quanta involved, and with their deep understanding of climate change over millennia and their ability to project what this might mean in the future, geoscientists are in a strong position to inform the illinformed, counter extreme views and advise government policy. The Geological Society is-should be-their platform to do so.

Mark Steeves, Samphire \& Associates Ltd, sits on the City of London Geoscience Forum and Corporate Affiliates Committee.

E-mail: MS@SamphireAssociates.com

\section{FURTHER READING}

An extended list of selected references may be read in the online version of this article. Editor.

www.blackrock.com/corporate/investorrelations/larry-fink-ceo-letter

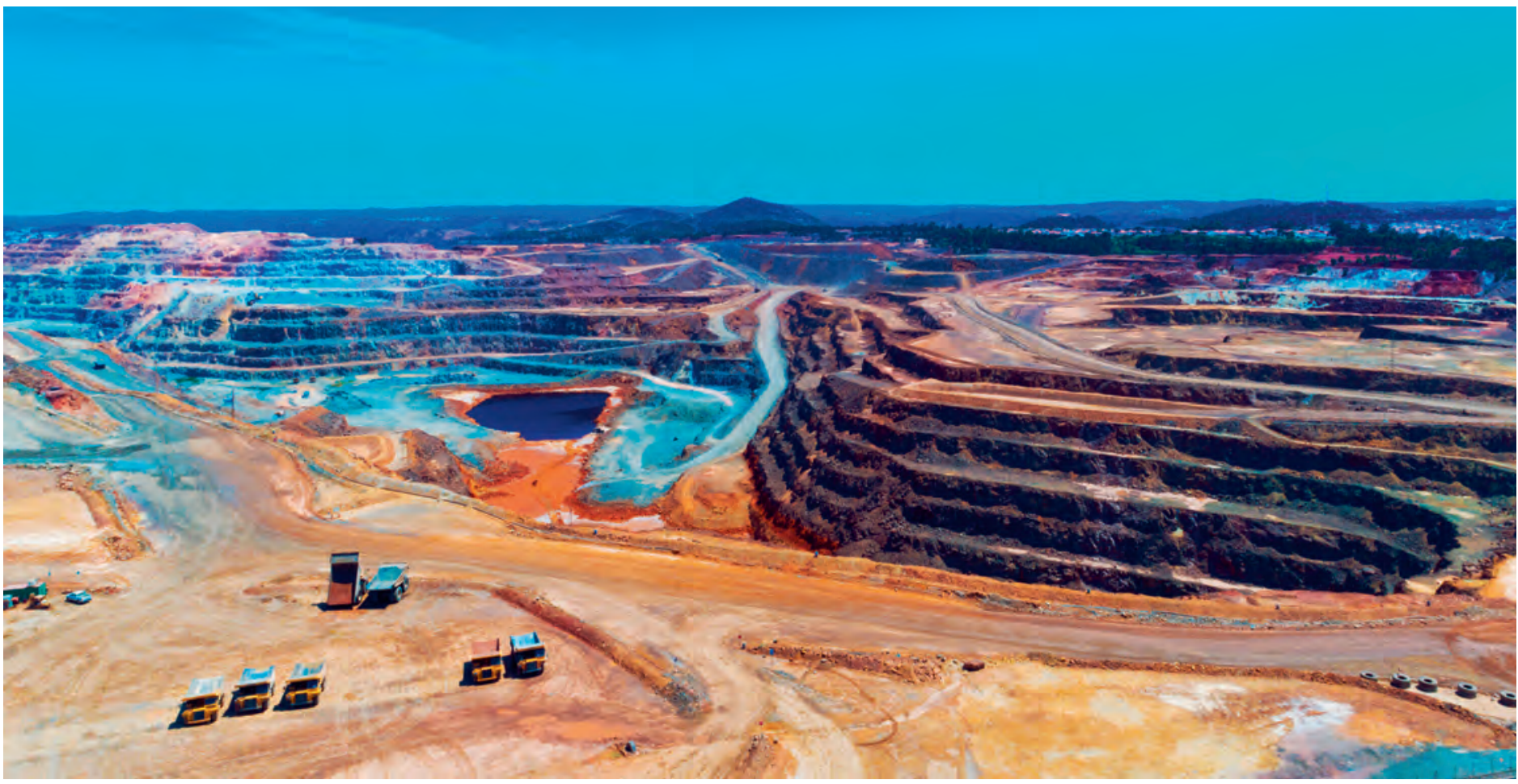

